\title{
PENGARUH BERBAGAI KONSENTRASI By-Vii TERHADAP KEMATIAN LARVA Aedes aegypti Tahun 2017
}

\author{
Putri Dwi Lestari ${ }^{*}$, Mela Firdaust ${ }^{* *}$ ) \\ Jurusan Kesehatan Lingkungan, Politeknik Kesehatan Kemenkes Semarang, \\ Jl.Raya Baturaden KM 12 Purwokerto, Indonesia
}

\begin{abstract}
Abstrak
Demam berdarah dengue ditularkan oleh nyamuk Aedes aegypti yang menjadi vektor utama. Cara yang paling banyak dilakukan untuk mengurangi populasi vektor nyamuk DBD stadium larva adalah dengan bahan kimia yang membahayakan kesehatan manusia. Banyak cara yang aman untuk membunuh vektor penyakit DBD dan mencegah berkembangnya, salah satunya dengan menggunakan insektisida hayati ByVii. By Vii adalah agen hayati yang didalamnya terdapat kandungan aktif jamur Beauveria bassiana Tujuan dari penelitian ini adalah untuk menganalisis konsentrasi By-Vii yang paling efektif terhadap kematian larva Aedes aegypti. Metode yang digunakan dalam penelitian ini adalah True Experiment dengan rancangan post test only control group design untuk menghitung kematian larva Aedes aegypti pada konsentrasi 10\%, 20\%, dan 30\% larutan By-Vii. Hasil penelitian larutan By-Vii terhadap kematian larva Aedes aegypti mempunyai signifikasi 0,91 $(>0,05)$ yang berarti tidak ada pengaruh konsentrasi ByVii terhadap kematian larva Aedes aegypti konsentrasi 10\% dengan kematian 9,3\%, konsentrasi $20 \%$ dengan kematian 8\%, dan konsentrasi 30\% dengan kematian 13,3\%.

Simpulan dari penelitian ini adalah larutan By-Vii mampu membunuh larva Aedes aegypti sebesar 13,3\%. Hal tersebut menunjukkan bahwa larutan By-Vii tidak efektif digunakan sebagai larvasida. Diharapkan penelitian selanjutnya menggunakan waktu pajanan By-Vii terhadap larva lebih dari 48 jam dan menambah konsentrasinya untuk mengetahui keefektifan produk By-Vii.
\end{abstract}

Kata kunci: larva Aedes aegypti, larutan By-Vii, Kesehatan Lingkungan

\begin{abstract}
The effect of various concentrations By-Vii on the death of larva mosquito Aedes aegypti. Dengue fever is transmitted by Aedes aegypti mosquito which becomes the main vector. The most method use the population of them when they are in larvae stage is using dangerous chemicals that can endanger people's life. There are a lot of method to cut down the vector of dengue fever disease by using the biological insecticide, By-Vii. It is a biological agent that consist of activated fungus, which is Beauveria bassiana. The purpose of this study to analyze the most effective concentration used to cut down the larvae form of Aedes aegypti. The method used in this research is True Experiment with post test only control group design to calculate Aedes aegypti larvae death at 10\%, 20\%, and 30\% concentration of By-Vii solution. The results of By-Vii solution of Aedes aegypti larvae mortality have significance 0,91 (>0,05), meaning, no effect of By-Vii concentration on Aedes aegypti larvae death concentration 10\% with death $9.3 \%$, concentration $20 \%$ with Death $8 \%$, and concentration $30 \%$ with mortality $13.3 \%$.

The conclusion of this research is By-Vii solution able to kill Aedes aegypti larvae by 13,3\%. It shows that By-Vii solution is not effectively used as a larvacide. It is hoped that further research uses By-Vii exposure time for larvae over 48 hours and adds concentration to know the effectiveness of By-Vii products.
\end{abstract}

Keywords: Aedes aegypti larvae, By-Vii solution, Environmental Health

\section{Pendahuluan}

Menurut Peraturan Menteri Kesehatan No 374

tahun 2010 penyakit yang ditularkan melalui vektor masih menjadi penyakit endemis yang dapat menimbulkan wabah atau kejadian luar biasa serta dapat menimbulkan gangguan kesehatan masyarakat sehingga 
perlu dilakukan upaya pengendalian atas penyebaran vektor. Menurut Pasal 1 (2) pengendalian vektor adalah semua kegiatan atau tindakan yang ditujukan untuk menurunkan populasi vektor serendah mungkin sehingga keberadaannya tidak lagi berisiko untuk terjadinya penularan penyakit tular vektor di suatu wilayah atau menghindari kontak masyarakat dengan vektor sehingga penularan penyakit tular vektor dapat dicegah.

Demam berdarah dengue ditularkan oleh nyamuk Aedes aegypti yang menjadi vektor utama dan Aedes albopictus yang menjadi vektor pendamping. Kedua spesies nyamuk itu ditemukan di seluruh wilayah Indonesia, hidup optimal pada ketinggian di atas 1000 di atas permukaan laut, tapi dari beberapa laporan dapat ditemukan pada daerah dengan ketinggian sampai dengan 1500 meter, bahkan di India dilaporkan dapat ditemukan pada ketinggian 2.121 meter serta di Kolombia pada ketinggian 2.200 meter.

Berdasarkan data Dinas Kesehatan Kabupaten Banyumas, kasus DBD di Kabupaten Banyumas mengalami peningkatan. Pada tahun 2015 ada 264 kasus DBD, meningkat menjadi 1281 kasus DBD pada tahun 2016. Ada 27 kecamatan yang merupakan daerah endemik di Kabupaten Banyumas. Pada tahun 2015 ada 33 desa dan kelurahan endemik DBD dan meningkat menjadi 47 desa dan kecamatan pada tahun 2016.

Pengendalian nyamuk yang sekarang dilakukan identik dengan penggunaaan insektisida. Namun penggunaan insektisida secara terus menerus di suatu wilayah tertentu akan menyebabkan resistensi terhadap spesies sasaran (Depkes, 2009). Cara yang paling banyak dilakukan untuk mengurangi populasi vektor nyamuk DBD stadium larva adalah dengan bahan kimia yang membahayakan kesehatan manusia. Banyak cara yang aman untuk membunuh vektor penyakit DBD dan mencegah berkembangnya, salah satunya dengan menggunakan insektisida hayati By-Vii. By Vii adalah agen hayati yang didalamnya terdapat kandungan aktif jamur Beauveria bassiana. Mekanisme infeksi Beauveria bassiana biasanya melibatkan toksin dan reaksi enzimatis. Enzim yang terlibat dalam mekanisme infeksi adalah enzim kitinase. Kitinase merupakan salah satu enzim yang berperan penting dalam entomopatogenitas. Kitinase merupakan enzim yang mampu menghidrolisis polimer kitin menjadi kitin oligosakarida atau monomer $N$-asetilglukosamin. Enzim kitinase dipakai oleh fungi dalam menyerang serangga dengan cara mendegradasi kitin pada kutikula dan membran pencernaan. Fungi entomopatogenik seperti Beauveria bassiana merupakan salah satu contoh fungi

\footnotetext{
${ }^{*}$ E-mail: putridwilestari_smaba@yahoo.co.id

${ }^{* *}$ E-mail: melafirdaust@yahoo.co.id
}

yang memanfaatkan enzim ini untuk menyerang serangga. Hal ini mengindikasikan bahwa kitinase yang dihasilkan oleh fungi bersifat mematikan terhadap serangga sehingga dapat dimanfaatkan untuk pengendalian serangga khususnya serangga pengganggu atau hama termasuk vektor. ( Firda Yanuar Pradani, dkk, 2015 ).

Berdasarkan hal tersebut di atas, maka penulis hendak melakukan penelitian dengan judul : "Pengaruh Berbagai Konsentrasi By-Vii Terhadap Kematian Larva Aedes aegypti Tahun 2017”.

\section{Bahan dan Metode}

Jenis penelitian ini yaitu true eksperiment dengan desain penelitian post test only control group design. Pengumpulan data dilakukan dengan cara pengukuran suhu dan kelembaban ruang penelitian, pengukuran suhu dan $\mathrm{pH}$ air uji, penghitungan kematian larva Aedes aegypti. Instrumen yang digunakan meliputi termohygrometer, $\mathrm{pH}$ stick universal, termometer air, dan stopwatch.

Penelitian dilaksanakan pada hari Rabu sampai Jumat tanggal 3 Mei - 5 Mei 2017. Lokasi penelitian berada di Laboratorium Entomologi Balai Penelitian dan Pengembangan Pengendalian Penyakit Bersumber Binatang Banjarnegara, Jawa Tengah yang beralamatkan di Jalan Selamanik No. 16A Kabupaten Banjarnegara. Fasilitas ruang, alat ukur suhu, kelembaban dan sampel larva Aedes aegypti instar 3 sudah disediakan di Balai Litbang P2B2 Banjarnegara. Larvasida By-Vii dan peralatan lainnya peneliti yang menyediakan.

\section{Hasil dan Pembahasan}

Berdasarkan hasil penelitian terhadap pengaruh berbagai konsentrasi $\mathrm{By}$-Vii terhadap kematian larva Aedes aegypti tahun 2017, dapat dilihat hasil dan pembahasan sebagai berikut :

1. Jumlah larva yang digunakan dalam penelitian Jumlah larva yang digunakan untuk penelitian sebanyak 300 ekor larva Aedes aegypti instar 3 dengan masing-masing larva trays berisi 25 ekor larva dan dilakukan replikasi sebanyak 3 kali.

2. Agen hayati By-Vii

Agen hayati By-Vii adalah bioinsektisida Beauveria bassiana yang bersifat sporadis (jamur memakan hama) manfaat untuk mengendalikan hama serangga dan ulat secara aman dan ramah lingkungan. Agen hayati By-Vii didapatkan dari toko "X" dan sudah dalam bentuk kemasan yang didalamnya berupa serbuk dengan bahan aktif jamur Beauveria bassiana. Konsentrasi yang digunakan dalam penelitian yaitu $10 \%$, 20\%, dan $30 \%$.

3. Suhu udara ruang penelitian

Suhu udara ruang penelitian diukur menggunakan termo-hygrometer. Pada pengukuran awal (hari pertama), suhu udara ruang penelitian sebesar $28^{\circ} \mathrm{C}$. Sedangkan pada pengukuran hari ketiga suhu ruang penelitian sebesar $28,2{ }^{\circ} \mathrm{C}$. Sehingga rata-rata 
suhu udara ruang penelitian sebesar $28,1^{\circ} \mathrm{C}$. Suhu udara merupakan salah satu faktor lingkungan yang mempengaruhi perkembangan larva nyamuk Aedes aegypti. Menurut Iskandar, dkk (1985) dalam Ilham Eka Praditya (2014), suhu yang optimal untuk larva berkisar antara $20^{\circ} \mathrm{C}-30^{\circ} \mathrm{C}$. Begitu pula menurut Kusnindar (1990) temperatur optimal untuk perkembangan larva adalah $25^{\circ} \mathrm{C}-30^{\circ} \mathrm{C}$. Hal tersebut menunjukkan bahwa suhu ruangan tidak mengganggu aktivitas larva. Menurut penelitian Abd. Gafur dan Muh. Saleh Jastam (2015) tidak ada hubungan antara suhu udara dengan keberadaan jentik nyamuk Aedes aegypti. Tidak adanya hubungan dikarenakan suhu udara tidak berhubungan langsung dengan jentik, atau dapat dikatakan suhu udara berhubungan langsung dengan pertumbuhan nyamuk bukan dengan jentiknya.

4. Kelembaban ruang penelitian

Kelembaban ruang penelitian diukur menggunakan termo-hygrometer. Pada pengukuran hari pertama didapatkan hasil kelembaban udara sebesar 71\% sedangkan pada hari ketiga kelembaban udara sebesar 68\%. Sehingga rata-rata kelembaban udara ruang penelitian 69,5\%. Syarat untuk berkembang biak larva Aedes aegypti yaitu berada pada kelembaban yang kondusif antara 60\%-80\% (Azhari,2004). Hal tersebut menunjukkan bahwa kelembaban udara tidak mempengaruhi kematian larva Aedes aegypti.

5. Suhu air uji

Tabel 1. Hasil pengukuran suhu air uji

\begin{tabular}{cccc}
\hline $\begin{array}{c}\text { Konsen } \\
\text { trasi }\end{array}$ & $\begin{array}{c}\text { Sebelum } \\
\text { Diberi } \\
\text { By-Vii }\end{array}$ & $\begin{array}{c}\text { Sesudah } \\
\text { Diberi } \\
\text { By-Vii }\end{array}$ & $\begin{array}{c}\text { Rata-rata } \\
\text { Suhu Air Uji }\end{array}$ \\
\hline Kontrol & $27^{\circ} \mathrm{C}$ & $27^{\circ} \mathrm{C}$ & $27^{\circ} \mathrm{C}$ \\
$10 \%$ & $27^{\circ} \mathrm{C}$ & $27^{\circ} \mathrm{C}$ & $27^{\circ} \mathrm{C}$ \\
$20 \%$ & $27^{\circ} \mathrm{C}$ & $27^{\circ} \mathrm{C}$ & $27^{\circ} \mathrm{C}$ \\
$30 \%$ & $27^{\circ} \mathrm{C}$ & $27^{\circ} \mathrm{C}$ & $27^{\circ} \mathrm{C}$ \\
\hline
\end{tabular}

Suhu air uji selama penelitian $27^{\circ} \mathrm{C}$ tidak menimbulkan gangguan fisik pada larva Aedes aegypti karena larva dapat berkembang pada suhu air antara 25$35^{\circ} \mathrm{C}$ dan larva tidak dapat berkembang pada suhu ekstrim dibawah $10^{\circ} \mathrm{C}$ atau diatas $40^{\circ} \mathrm{C}$. (Kestina, 1995 (dalam penelitian Dewi Susanna dkk, 2003)). Sedangkan menurut Depkes (1992) suhu air yang optimal bagi kehidupan larva Aedes aegypti berkisar antara $25^{\circ} \mathrm{C}$ $30^{\circ} \mathrm{C}$. Hal tersebut menunjukkan bahwa suhu air selama penelitian masih sesuai dengan perindukan larva Aedes aegypti.

6. $\mathrm{pH}$ air uji

Tabel 2. Hasil pengukuran $\mathrm{pH}$ air uji

\begin{tabular}{cccc}
\hline Konsentrasi & $\begin{array}{c}\text { Sebelum } \\
\text { Diberi } \\
\text { By-Vii }\end{array}$ & $\begin{array}{c}\text { Sesudah } \\
\text { Diberi } \\
\text { By-Vii }\end{array}$ & $\begin{array}{c}\text { Rata-rata } \\
\mathrm{pH}\end{array}$ \\
\hline Kontrol & 7 & 7 & 7 \\
$10 \%$ & 7 & 7 & 7 \\
$20 \%$ & 7 & 7 & 7 \\
$30 \%$ & 7 & 7 & 7 \\
\hline
\end{tabular}

pH air uji selama penelitian sebelum dan sesudah diberi By-Vii yaitu 7. Larva Aedes aegypti dapat bertahan hidup di dalam air dengan $\mathrm{pH}$ 5,8 - 8,8 (Kestina, 1995 (dalam penelitian Dewi Susanna dkk, 2003)), sehingga dapat disimpulkan bahwa $\mathrm{pH}$ air uji tidak mempengaruhi kematian larva Aedes aegypti. Menurut Hidayat C dkk, dalam penelitiannya tentang pengaruh $\mathrm{pH}$ air perindukan terhadap perkembangbiakan Aedes aegypti bahwa pada $\mathrm{pH}$ air perindukan 7, lebih banyak didapati nyamuk daripada $\mathrm{pH}$ asam atau basa. Sedangkan menurut Adang Iskandar dkk, pH air yang optimum sebagai perkembangbiakan larva berkisar 6,8 8,5. Larva Aedes aegypti dapat hidup dalam wadah yang berisi air dengan pH berkisar 5,8-8,6 (Hoedojo, 1993) sehingga $\mathrm{pH}$ pada air uji tidak berpengaruh terhadap perindukan larva.

7. Kematian larva dibedakan menurut konsentrasi ByVii

Tabel 3. Hasil kematian larva Aedes aegypti

\begin{tabular}{|c|c|c|c|c|c|c|}
\hline \multirow{2}{*}{$\begin{array}{c}\text { Kon } \\
\text { sen } \\
\text { trasi } \\
B y- \\
\text { Vii }\end{array}$} & \multirow{2}{*}{$\begin{array}{c}\text { Ula } \\
\text { ngan }\end{array}$} & \multirow{2}{*}{$\begin{array}{c}\text { Jum } \\
\text { lah } \\
\text { larva } \\
\text { dipa } \\
\text { par } \\
\text { kan }\end{array}$} & \multicolumn{2}{|c|}{$\begin{array}{c}\text { Kema } \\
\text { tian } \\
\text { larva } \\
\text { jam ke }\end{array}$} & \multirow{2}{*}{$\begin{array}{c}\text { Rata- } \\
\text { Rata } \\
\text { Kema } \\
\text { tian } \\
\text { Larva } \\
\text { Tiap } \\
\text { Kon } \\
\text { sen } \\
\text { trasi }\end{array}$} & \multirow{2}{*}{$\begin{array}{c}\text { Per } \\
\text { sen } \\
\text { tase } \\
\text { Rata } \\
\text { rata } \\
\text { kema } \\
\text { tian } \\
\text { larva } \\
(\%)\end{array}$} \\
\hline & & & 24 & 48 & & \\
\hline Kon & 1 & 25 & 0 & 0 & 0 & 0 \\
\hline \multirow[t]{2}{*}{ Trol } & 2 & 25 & 0 & 0 & & \\
\hline & 3 & 25 & 0 & 0 & & \\
\hline \multirow[t]{3}{*}{$10 \%$} & 1 & 25 & 0 & 3 & 2 & 9,3 \\
\hline & 2 & 25 & 0 & 3 & & \\
\hline & 3 & 25 & 1 & 1 & & \\
\hline \multirow[t]{3}{*}{$20 \%$} & 1 & 25 & 0 & 3 & 2 & 8 \\
\hline & 2 & 25 & 0 & 0 & & \\
\hline & 3 & 25 & 2 & 3 & & \\
\hline \multirow[t]{3}{*}{$30 \%$} & 1 & 25 & 0 & 5 & 3 & 13,3 \\
\hline & 2 & 25 & 1 & 4 & & \\
\hline & 3 & 25 & 0 & 1 & & \\
\hline
\end{tabular}

Kematian larva mulai terlihat pada jam ke 24 . Larva dikatakan mati karena larva sudah tidak bergerak lagi di dalam air dan mengapung dipermukaan air. Setelah dilakukan pengamatan sampai jam ke 48, kematian larva tertinggi pada konsentrasi 30\%. Pada jam ke 24 hanya ada 1 ekor larva yang mati pada dosis 10\%, 2 ekor larva mati pada dosis $20 \%$, dan 1 ekor larva mati pada dosis 30\%. Pada jam ke 48 kematian larva bertambah walaupun tidak terlalu tinggi. Kematian larva tertinggi pada konsentrasi By-Vii 30\% yaitu dengan ratarata kematian $13,3 \%$.

Kematian larva diakibatkan oleh bahan aktif dari By-Vii yaitu jamur Beauveria bassiana. Hal tersebut dibuktikan dengan tubuh larva yang mati berwarna putih karena diselimuti oleh jamur. Mekanisme infeksi Beauveria bassiana masuk ke tubuh serangga inang 
melalui kulit, saluran pencernaan, spirakel dan lubang lainnya. Jamur akan mengeluarkan racun beauverin yang akan membuat kerusakan jaringan tubuh serangga. Serangga akan mati dalam beberapa hari. Setelah itu, miselia jamur akan tumbuh ke seluruh bagian tubuh serangga. Serangga yang terserang jamur Beauveria bassiana akan mati dengan tubuh mengeras seperti mumi dan tertutup oleh benang-benang hifa berwarna putih. (Bina Ikawati, 2016).

Lamanya waktu paparan By-Vii terhadap larva Aedes aegypti juga mempengaruhi banyaknya kematian larva. Pada penelitian yang dilakukan oleh Maharani Herawan Ossa Putri (2015) didapatkan kematian larva mencapai $63,3 \%$ pada tingkat pengenceran 10-1 yang telah dipaparkan selama 48 jam. Perbedaan bahan yang digunakan dapat mempengaruhi jumlah kematian larva. Maharani menggunakan bahan aktif Beauveria bassiana dalam media jagung yang diperoleh dari Balai Proteksi Tanaman Perkebunan Bandung dengan ditambahkan bahan-bahan lainnya sehingga didapatkan suspensi spora. Pada penelitian kali ini, peneliti menggunakan produk By-Vii yang dijual dipasaran akan tetapi dengan bahan aktif yang sama yaitu jamur Beauveria bassiana. Setelah diamati selama 48 jam kematian larva Aedes aegypti tidak mencapai $100 \%$, kematian tertinggi pada konsentrasi 30\% dengan rata-rata kematian 13,3\%.

Sastrodihardjo (2006) dalam Maharani Herawan Ossa Putri (2015), menyatakan bahwa masuknya insektisida ke dalam tubuh serangga dapat melalui tiga bagian, salah satunya adalah melalui permukaan tubuh (kulit). Senyawa toksik yang terdapat dalam spora jamur mengalami kontak langsung dengan permukaan tubuh larva sehingga mengakibatkan terganggunya metabolisme tubuh. Gangguan dalam metabolisme tubuh inilah yang dapat menyebabkan kematian larva. Apalagi larva Aedes aegypti merupakan kelompok invertebrata yang memiliki sistem metabolisme yang sederhana sehingga secara fisiologis invertebrata lebih rentan terhadap zat racun (toksik).

Penelitian yang telah dilakukan oleh Maharani Herawan Ossa Putri (2015), rata-rata kerapatan spora jamur Beauveria bassiana yang dapat mematikan 50\% larva Aedes aegypti instar III selama pendedahan 24 jam sebesar 49,0×109 spora/mL, sedangkan pada waktu pendedahan 48 jam jumlah rata-rata kerapatan spora jamur Beauveria bassiana yang dapat mematikan 50\% larva Aedes aegypti instar III sebesar 19,0×108 spora/mL. Semakin tinggi kerapatan spora semakin tinggi pula kematian serangga uji (Dunn dan Mechalas, 1963 (dalam Maharani Herawan Ossa Putri,2015)). Banyaknya spora yang menempel pada tubuh serangga makin besar peluang spora tersebut untuk tumbuh dan berkembang pada serangga sasaran yang selanjutnya dapat mematikan serangga.

Faktor-faktor yang menurut peneliti dapat menghambat kematian larva yaitu : a. Waktu paparan yang kurang lama.

Peneliti hanya memaparkan By-Vii selama 2x24 jam. Penelitian sebelumnya yang telah dilakukan oleh Bina Ikawati, Beauveria bassiana dipaparkan ke larva An. Maculatus selama 192 jam. Awalnya pengamatan direncanakan sampai 96 jam setelah aplikasi, namun karena efek yang lambat sehingga pengamatan dilakukan sampai dengan 192 jam pasca aplikasi.

b. Bahan Beauveria bassiana yang digunakan

Pada penelitian yang dilakukan oleh Maharani, Yekki Yasmin, dan Bina Ikawati, jamur Beauveria bassiana didapatkan dari hasil pembiakan dan pembuatan suspensi jamur yang dibuat sendiri. Sedangkan pada penelitian kali ini, peneliti menggunakan produk By-Vii yang ada dipasaran dan didalamnya terdapat bahan aktif Beauveria bassiana. Hal tersebut dapat mempengaruhi perbedaan kematian larva dengan penelitian sebelumnya karena produk ByVii yang digunakan merupakan produk yang dijual di pasaran yang mulai distributor hingga penjual di pasar penyimpanannya tidak memperhatikan suhu. Suhu optimum untuk pertumbuhan jamur Beauveria bassiana yaitu $25^{\circ} \mathrm{C}-30^{\circ} \mathrm{C}$. Karena suhu yang tidak diperhatikan tersebut, bisa membuat keaktifan jamur Beauveria menjadi berkurang sehingga tidak mampu membunuh larva Aedes aegypti secara maksimal.

c. Bahan pengencer yang digunakan

Penelitian yang dilakukan oleh Maharani Herawan Ossa Putri (2015), jamur Beauveria bassiana dalam media jagung diperoleh dari Balai Proteksi Tanaman Perkebunan Bandung. Pembuatan suspensi spora jamur Beauveria bassiana dilakukan dengan menimbang 100 gram medium beras jagung yang telah ditumbuhi spora jamur, lalu ditambahkan 40 tetes larutan Tween80 kemudian ditambah larutan aquades hingga mencapai volume $500 \mathrm{~mL}$. Medium beras jagung berspora tersebut harus dilarutkan dalam larutan tween80 karena spora jamur Beauveria bassiana bersifat hidrofob sehingga agar spora dapat tersuspensi dengan baik dan melekat kuat maka digunakan larutan tween80 sebagai pelarutnya. Sedangkan pada penelitian kali ini, peneliti menggunakan air sumur untuk melarutkan $B y-$ Vii. Air sumur yang digunakan dikhawatirkan mengandung zat-zat mineral yang dapat menghambat kinerja dari jamur Beauveria bassiana sehingga menghambat proses kematian larva.

8. Analisis Uji Statistik

Uji Anova dilakukan untuk menguji apakah ada pengaruh konsentrasi By-Vii terhadap kematian larva Aedes aegypti. Syarat uji Anova diantaranya data harus berdistribusi normal dan homogen. Berdasarkan uji normalitas dan homogenitas yang telah dilakukan, data yang didapatkan tidak berdistribusi normal dan tidak homogen. Pada uji normalitas diketahui nilai signifikan $<0,05$ sehingga data tidak berdistribusi normal. Pada uji 
homogenitas nilai signifikan $0,34<0,05$ sehingga dapat disimpulkan data tidak homogen.

Karena syarat untuk uji Anova tidak terpenuhi, maka digunakan uji Kruskal Wallis. Setelah dilakukan uji Kruskal Wallis didapatkan hasil seperti pada tabel 4.6. nilai $\mathrm{p}$ (sig) 0,91 >0,05 sehingga Ha ditolak yang berarti tidak ada pengaruh konsentrasi By-Vii terhadap kematian larva Aedes aegypti. By-Vii tidak berpengaruh terhadap kematian larva Aedes aegypti dikarenakan waktu paparan yang kurang lama dan konsentrasi yang kurang optimal. Proses peracunan jamur Beauveria bassiana terhadap larva berjalan lambat. Sehingga butuh waktu lebih lama untuk bisa melihat keefektivan By-Vii.

\section{Kesimpulan}

a. Tidak ada pengaruh konsentrasi By-Vii terhadap kematian larva Aedes aegypti

b. Ada perbedaan kematian larva Aedes aegypti pada setiap konsentrasi By-Vii. Pada konsentrasi $10 \%$ rata-rata kematian larva sebesar 9,3\%, konsentrasi $20 \%$ rata-rata kematian larva sebesar 8\% dan pada konsentrasi 30\% kematian larva $13,3 \%$.

c. By-Vii tidak efektif digunakan sebagai larvasida karena hanya mampu membunuh larva dengan rata-rata kematian $13,3 \%$ (<90\%)

\section{Ucapan Terimakasih}

Peneliti banyak mengucapkan terimakasih kepada pihak Balai Litbang P2B2 Banjarnegara yang telah memberikan ijin dan tempat untuk melaksanakan penelitian serta seluruh pihak yang telah membantu terselesaikannya penelitian ini.

\section{Daftar Pustaka}

Aryu Candra, 2010, Demam Berdarah Dengue: Epidemiologi, Patogenesis, dan Faktor Risiko Penularan, Aspirator Vol. 2 No. 2 Tahun 2010 : $110-119$

Betty Mauliya Bustam, Lenni Fitri, Yekki Yasmin, 2011, Analisis Efektifitas Tepung Jamur sebagai LarvasidaAedes aegypti, Banda Aceh: Jurnal Natur Indonesia 14(2) 126-130.

Bina Ikawati, 2015, Studi Efek Beauveria Bassiana Pada Anopheles Maculatus Fase Aquatik Di Laboratorium, Banjarnegara: Balai Litbang P2B2 Banjarnegara

_ 2016, "Beauveria bassianasebagai Alternatif Hayati dalam Pengendalian Nyamuk", Banjarnegara: Balai Litbang P2B2 Banjarnegara

Dewi Susanna, 2003, Potensi Daun Pandan Wangi Untuk Membunuh Larva Nyamuk Aedes aegypti, Depok: Fakultas Kesehatan Masyarakat Universitas Indonesia

Ditjen PP \& PL, 2007, Survai Entomologi Demam Berdarah Dengue, Jakarta: Kementerian Kesehatan Republik Indonesia
Ditjen PP\& PL, 2012, Pedoman Pengendalian Deman Chikungunya Edisi 2, Jakarta: Kementerian Kesehatan Republik Indonesia

Ditjen PP \& PL, 2013,Pedoman Pengendalian Demam Berdarah Dengue di Indonesia, Jakarta: Kementerian Kesehatan Republik Indonesia

Ditjen PP \& PL, 2013, Pengendalian Demam Berdarah DengueUntuk Pengelola Program DBD Puskesmas, Jakarta: Kementerian Kesehatan Republik Indonesia

Firda Yanuar Pradani, Mutiara Widawati, 2015, Mortalitas Aedes albopictus akibat infeksi horizontal Beauveria bassiana dan aktivitas enzim Kitinase B.bassiana. Ciamis: Loka Litbang P2B2 Ciamis

Herry Purnama, Nur Hidayati, Eni Setyowati, 2015, Pengembangan Produksi Pestisida Alami Dari Beauveria Bassiana Dan Trichoderma Sp. Menuju Pertanian Organik, Surakarta: Universitas Muhammadiyah Surakarta, Vol .18, No.1

Hikmat Kasmara, Maharani Herawan Ossa Putri, Melanie, 2015, Jamur entomopatogen Beauveria bassiana (Balsamo, 1912) sebagai agen hayati pengendali nyamuk Aedes aegypti (Linnaeus, 1762), Bandung: Departemen Biologi, Fakultas Matematika dan Ilmu Pengetahuan Alam Universitas PadjadjaranVolume 1, halaman 1472-1477

Hindra I. Satari dan Mila Meiliasari, 2008, Demam Berdarah Perawatan di Rumah Sakit \& Rumah Sakit + Menu, Jakarta: Puspa Swara

Ilham Eka Praditya, 2014, Perilaku 3M Plus Ibu Rumah Tangga dan Kondisi Lingkungan Terhadap Kepadatan Larva Aedes aegypti di Wilayah Zona Merah Kelurahan Kebon Kacang Tahun 2014,Jakarta: UIN Syarif Hidayatullah Kementerian Kesehatan Republik Indonesia, 2015, "Demam Berdarah Biasanya Mulai Meningkat di Januari”, http://www.depkes.go.id/article/view/150117000 03/demam-berdarah-biasanyamulai-meningkatdi-januari.html\#sthash.Wjkrw7z7.dpufdiakses pada 15 Oktober2016 pukul 19.50

Kresyan Pentury dan Windy Nusaly, 2011, Analisa Kepadatan Larva Nyamuk Culicudae DanAnophelidae Pada Tempat Perindukan Di Negeri Kamarian Kecamatan KairatuKabupaten Seram Bagian Barat (Sbb), Ambon: Program Studi Pendidikan Dokter Universitas Pattimura

M. Rasyid Ridha, Nita Rahayu, Nur Afridha Rosvita, dan Dian Eka Setyaningtyas, 2013, Hubungan Kondisi Lingkungan Dan Kontainer Dengan Keberadaan Jentik Nyamuk Aedes Aegypti Di Daerah Endemis Demam Berdarah Dengue Di 
Kota Banjarbaru, Banjarmasin: Balai Litbang P2B2 Tanah Bumbu, Vol. 4, No. 3, Juni 2013

M. Sopiyudin Dahlan, 2009, "Statistik Untuk

Kedokteran dan Kesehatan Edisi 4”,Jakarta: Salemba Medika Republik Indonesia, 2010, Peraturan Menteri Kesehatan Nomor 374 Tahun 2010 Tentang Pengendalian Vektor, Jakarta: Menteri Kesehatan

Riska Alfianastuti, 2015, Pengaruh Pemakaian Perasan Daun Belimbing Wuluh (Averrhoa Bilimbi L.) Terhadap Kematian Larva Aedes Aegypti Tahun 2015, Karya Tulis Ilmiah, Purwokerto: Kementerian Kesehatan RI Politeknik Kesehatan Kemenkes Semarang Jurusan Kesehatan Lingkungan.

Soedarto, 2009, Penyakit Menular di Indonesia, Jakarta: CV Agung Seto

Soegeng Soegijanto, 2006,Demam Berdarah Dengue Edisi Kedua,Surabaya; Airlangga University Press 